\title{
Comparison of the Results of Studies of Air Pollution Fungi Using the SAS Super 100, MAS 100, and Air IDEAL
}

\author{
Cecylia Łukaszuk ${ }^{1}$, Elżbieta Krajewska-Kułak ${ }^{1}$, Andrzej Guzowski ${ }^{1}$, Wojciech Kułak ${ }^{2, *}$ \\ and Bogumiła Kraszyńska ${ }^{1}$ \\ 1 Department of Integrated Medical Care, Medical University of Bialystok, 15-274 Białystok, Poland; \\ cecylia.lukaszuk@wp.pl (C.Ł.); elzbieta.krajewska@wp.pl (E.K.-K.); andrzejguzowski5@gmail.com (A.G.); \\ bogumila.kraszynska@gmail.com (B.K.) \\ 2 Department of Pediatric Rehabilitation, Medical University of Białystok, 15-274 Białystok, Poland \\ * Correspondence: kneur2@wp.pl; Tel.: +48-85-7450-601
}

Received: 15 June 2017; Accepted: 16 July 2017; Published: 20 July 2017

\begin{abstract}
Although several air sampling devices for identifying and enumerating airborne microorganisms are commercially available, each poses some limitations. The aim of this study was to evaluate air pollution fungi using three such samplers: SAS Super 100, Microbiological Air Sampler (MAS) 100, and Air IDEAL. Mycological air was taken from the cellars of a 17th-century church in Siemiatycze, Poland, and the nearby outdoor environment. With samplers placed $1.5 \mathrm{~m}$ above the floor, microbial flora in air samples collected inside and outside the cellar were detected. The number of colony-forming units (CFU) of fungi obtained with the three samplers from the cellars and outdoor environment differed; the most CFU were obtained with the Air IDEAL and the least with the SAS Super 100. Significant differences emerged in CFUs collected from air samples with the MAS 100 and SAS Super 100, on the one hand, and the SAS Super 100 and Air IDEAL, on the other. Otherwise, results among the samplers were different. More Cladosporium species were collected with the MAS 100 sampler, whereas more Fusarium and Aspergillus species were collected with the Air IDEAL sampler. Significant differences among $\mathrm{CFU} / \mathrm{m}^{3}$ values among the tested sites depended on the sampler used.
\end{abstract}

Keywords: air samplers; air; air pollution; cellar; fungi

\section{Introduction}

Monitoring the microbiological purity of the environment, especially in areas with healthcare institutions, is critical due to the significant number of infections transmittable in the environment, including the air. Human exposure to airborne biological agents in residential, occupational, and industrial settings can cause various negative health effects [1,2]. A great deal of fungal allergen exposure occurs both outdoors and indoors, and many indoor allergens also appear outside buildings, which they pass through windows, doors, vents, cracks, or fissures in walls.

Numerous studies have demonstrated that the onset of sick building syndrome (SBS), or building-related illness, could partially stem from exposure to biological agents [3-5]. Wouters et al. (2002) [6] found that waste collectors exposed to a mixture of bioaerosols showed signs of increased upper airway inflammation and respiratory symptoms compared with controls. Mold fungi can considerably harm human health, namely by producing innumerable spores that can be carried for thousands of kilometers in external environments [7]. Indeed, two groups of diseases have been distinguished within sick building syndrome: specific ones deriving from allergies, compromised 
immunity, and infections; and, by contrast, non-specific ones involving the irritation of skin and mucous membranes, headaches, fatigue, and concentration disorders [8].

Systematic research is necessary to modify and improve air assessment methods in order to guarantee the most accurate identification of qualitative and quantitative microorganisms in air environments. An ideal method of air sampling should allow the enumeration of microorganisms per unit volume of the air sample and ensure the retention of all microorganisms in the sample. An ideal method should also not affect the viability of microorganisms retained and allow the elimination of substances that slow the development of microorganisms possibly present in the air, including antibiotics and chemotherapy drugs. Although several sampling devices for identifying and enumerating airborne microorganisms are commercially available, each poses some limitations [9-14].

When selecting a particular sampler for collecting microbial agents of concern, it is important to know its cut-off size. The point corresponding to a collection efficiency of $50 \%$ is used to set the cut-off size, or cut-off diameter, $\mathrm{d}_{50 \%}$. All particles above the size would be collected, and all below that size would pass onto the next stage.

The SAS Super 100 has a cut-off size of $1.30 \mu \mathrm{m}$, MAS 100 has a cut-off size of $1.47 \mu \mathrm{m}$, while AIR IDEAL has a cut-off size of $3 \mu \mathrm{m}$. Such cut-off size allows these samplers to collect most fungal spores $[9,15]$.

Furthermore, although few studies have compared three or more air samplers, conducting comparative studies on the evaluation of mycological flora in the air using different air samplers can be fruitful $[10,11]$. On the one hand, such studies might help to identify an adequate method of sampling, whereas on the other, they might clarify the extent to which comparing test results obtained from air samples gathered with various samplers is possible.

This study is part of the project of assessing air pollution in crypts, basements of old churches in the Podlasie province. The aim of this study was to evaluate the results of air pollution fungi using the samplers SAS Super 100, Microbiological Air Sampler (MAS) 100, and Air IDEAL in the cellars of a 17th-century church in Siemiatycze, Poland.

\section{Materials and Methods}

\subsection{Materials}

Materials consisted of mycological air sampled from the cellars of a 17th-century stone church, Assumption of the Blessed Virgin Mary, in Siemiatycze, Poland, and from its outdoor environment.

\subsection{Methods}

Conducted in March 2016, sampling involved gathering microorganisms from the air using three samplers. The first was the SAS Super 100 (pbi International, Rockville, MD, USA), which belongs to the latest generation of devices that meet the requirements of international standards of measurement. The sampler has been approved by the US Food and Drug Administration, the American Conference of Governmental Industrial Hygienists, and the American Society for Testing and Materials Committee. - USP 23-NF 18-8th Supplement (May 1998)-Microbiological Evaluation of Clean Rooms and Other Controlled Environments. - European Union Guide for GMP - Manufacture of Sterile Medicinal Products Control of Medicines and Inspection and CEN/TC 243 Norms for Clean Room Technology. The second was MAS 100 (Merck, Darmstadt, Germany), which fulfills criteria described in the standard ISO/CD 14698-1. The third sampler was Air IDEAL (BioMerieux, Marcy-l'Étoile, France), which has been approved by the Canada Standards Association and Underwriters Laboratories and received a Quality Control Certificate of Adjustment Methods and Certificate of Performance Standards. The basis for the use of the device is described in the draft standard ISO/DIS 1498-1. All microbial samplers are designed to sample culturable, airborne microorganisms in order to determine their presence in the air and the possibility of human exposure to airborne biological agents. 
We compared the yields of three sieve impactor air samplers. They are the single stage impactors. A single stage impactor has a plurality of different sized nozzles that predicate a particle collection efficiency curve that approximates a predetermined curve.

The MAS-100 is a high-performance instrument which aspirates air through a perforated plate. The resulting airflow is directed onto a standard Petri dish containing agar. The MAS-100 operates with a high-performance suction device, and the aspirated volume is continuously monitored. The system measures the inflow of air and regulates the aspirated volume to a constant value of $100 \mathrm{~L}$ per minute.

The SAS Super 100 is currently considered the reference for microbiological air sampling at the instrumental level with environmental bioareosol capture rate of $100 \%$. Air is aspirated at a fixed speed for variable time through a cover which has been machined with a series of small holes of a special design. The resulting laminar air flow is directed onto the agar surface. When the preset sampling cycle is completed, the plate is removed and incubated.

The Air IDEAL has an ergonomic design and is user-friendly, easy to operate, and programmable, allowing sequential air sampling. It uses standard prepared media. It is an impactor type of instrument in which air is aspirated through a grid perforated with calibrated holes. The resulting air streams containing microbial particles are directed onto the agar surface. In the tested samplers, we used Sabouraud dextrose agar plates with a diameter of $90 \mathrm{~mm}$ from (BioMerieux, Warsaw, Poland).

During air sampling, the samplers were placed $1.5 \mathrm{~m}$ from the floor. The three samplers were positioned all together and the samples were collected simultaneously. Also, the outside air samplers were placed $1.5 \mathrm{~m}$ from the ground and $3 \mathrm{~m}$ from the building. During air sampling, there was no cover snow. The duration of each air sampling was $1 \mathrm{~min}$ with an airflow of $100 \mathrm{~L}$. The number of colony forming units (CFU) in the samples was calculated by referring to the positive hole conversion table for the samplers per the manufacturer's instructions. Measurements were made three times. Following an incubation period of three days at $27^{\circ} \mathrm{C}$, a quantitative analysis and morphological evaluation of the fungal colonies were performed. Depending on the nature of the fungal culture, plates were incubated for up to 14 days to allow for identification. The raw count of colonies on each agar plate was adjusted by referring to statistical scaling tables and applying them to each sampler. Cultured fungi were identified in terms of macroscopic and microscopic characteristics. Yeast-like fungi were identified using their original CHROMagar Candida (Paris, France) selective and differential media. This technology is based on soluble colorless molecules (called chromogens), composed of a substrate (targeting a specific enzymatic activity) and a chromophore. When the target organism's enzyme cleaves the colorless chromogenic conjugate, the chromophore is released. With the inclusion of chromogenic substrates in the medium, C. albicans, C. tropicalis, and C. krusei colonies produced different colors, thus allowing the direct detection of the yeast species on isolation plates. Colonies of C. albicans appeared in a light or medium green, C. tropicalis colonies in a blue or metallic blue, and C. krusei in a light mauve or mauve. Flat colonies showed a whitish border, and other yeasts (e.g., C. glabrata and C. kefyr) appeared in a light to dark mauve.

For molds, a microscopic evaluation of the morphological elements used in preparations was performed. Temperature and humidity were measured using a thermo-hygrometer (TSI VelociCheck Model 9545, Shoreview, MN, USA).

\subsection{Statistics}

Statistical software Statistica version 10 (Statsoft, Kraków, Poland) was used for statistical analysis. To test distribution our data, the Shapiro-Wilk test was used. The results were not normally distributed and non-parametric method the Wilcoxon signed-rank was used to compare CFU values. A level of statistical significance of $p<0.05$ was used.

\subsection{Ethics}

The study was approved by the ethics committee of the Medical University of Białystok, Poland (R-I-002/489/2014). 


\section{Results}

Temperature, humidity, and air movement in the studied areas and outside the church were also evaluated. In all areas examined, the average temperature of the basement was $7.3 \pm 0.96{ }^{\circ} \mathrm{C}$, the average air movement was $0.13 \pm 0.07 \mathrm{~m} / \mathrm{s}$, and the humidity was $76.8 \pm 7.1 \%$. Outside the church, the temperature was $5.6^{\circ} \mathrm{C}$, the average air movement was $1.9 \mathrm{~m} / \mathrm{s}$, and the humidity was $82.7 \%$. Details about the results of those evaluations appear in Table 1.

Table 1. Temperature, humidity, and air flow in the tested areas.

\begin{tabular}{ccccc}
\hline & Place of Collection & Temperature $\left({ }^{\circ} \mathbf{C}\right)$ & Air Flow $(\mathbf{m} / \mathbf{s})$ & Humidity (\%) \\
\hline \multirow{3}{*}{ Cellar I } & Entrance & $8.0 \pm 0.3$ & $0.08 \pm 0.01$ & $68.4 \pm 2.4$ \\
& Center & $7.7 \pm 0.4$ & $0.09 \pm 0.008$ & $71.5 \pm 2.8$ \\
& Near window & $7.1 \pm 0.5$ & $0.24 \pm 0.002$ & $74.6 \pm 2.4$ \\
\hline \multicolumn{2}{c}{ Mean values } & $7.6 \pm 0.4$ & $0.1 \pm 0.01$ & $71.5 \pm 2.5$ \\
\hline \multirow{2}{*}{ Cellar II } & Center & $9.0 \pm 0.8$ & $0.02 \pm 0.007$ & $69.1 \pm 6.7$ \\
\hline \multirow{2}{*}{ Cellar III } & Entrance & $6.1 \pm 1.4$ & $0.09 \pm 0.009$ & $86.1 \pm 6.9$ \\
& Center & $6.4 \pm 1.2$ & $0.18 \pm 0.01$ & $84.4 \pm 7.0$ \\
& Near window & $6.5 \pm 1.1$ & $0.18 \pm 0.02$ & $83.8 \pm 6.6$ \\
\hline \multicolumn{2}{c}{ Cellars mean values } & $7 \pm 1.2$ & $0.12 \pm 0.01$ & $80.9 \pm 6.8$ \\
\hline \multicolumn{2}{c}{ Mean values } & $7.3 \pm 0.96$ & $0.13 \pm 0.07$ & $76.8 \pm 7.1$ \\
\hline \multicolumn{2}{c}{ Outside } & $5.6 \pm 1.6$ & $1.9 \pm 0.2$ & $82.7 \pm 2.8$ \\
\hline
\end{tabular}

Regarding CFU counts (CFU/ $\mathrm{m}^{3}$ ) of the MAS 100 sampler, collected air samples ranged from 270 to 490 (384.1 \pm 77.7 ). The SAS SUPER 100 sampler showed CFUs of air samples ranging from 180 to 310 (251.4 \pm 49.4 ), whereas the Air IDEAL sampler yielded CFU counts ranging from 200 to 750 (428.6 \pm 175.9$)$. Significant differences in CFU of fungi emerged between the MAS 100 and SAS Super 100, and the SAS Super 100 and Air IDEAL on the other hand. Details of those results appear in Table 2.

Table 2. CFU collected air samples in the studied areas, depending on the sampler type.

\begin{tabular}{|c|c|c|c|c|}
\hline \multirow{2}{*}{\multicolumn{2}{|c|}{ Place of Air Sampling }} & \multicolumn{3}{|c|}{ CFU $\left(\mathrm{CFU} / \mathrm{m}^{3}\right) /$ Sampler Type } \\
\hline & & MAS 100 & SAS Super 100 & Air IDEAL \\
\hline \multirow{3}{*}{ Cellar I } & Entrance & $480 \pm 75.6$ & $270 \pm 45.8$ & $320 \pm 145.8$ \\
\hline & Center & $270 \pm 79.5$ & $180 \pm 48.6$ & $200 \pm 149.6$ \\
\hline & Near window & $490 \pm 66.1$ & $310 \pm 58.4$ & $430 \pm 198.4$ \\
\hline Cellar II & Center & $330 \pm 69.8$ & $200 \pm 66.9$ & $310 \pm 187.7$ \\
\hline \multirow{3}{*}{ Cellar III } & Entrance & $320 \pm 89.6$ & $300 \pm 44.8$ & $610 \pm 204.8$ \\
\hline & Center & $420 \pm 87.9$ & $290 \pm 38.7$ & $750 \pm 185.6$ \\
\hline & Near window & $360 \pm 75.8$ & $210 \pm 42.8$ & $380 \pm 159.7$ \\
\hline \multirow{2}{*}{\multicolumn{2}{|c|}{$\begin{array}{l}\text { Mean value from all areas } \\
\text { Outside church }\end{array}$}} & $384.1 \pm 77.7^{\#, \&}$ & $251.4 \pm 49.4^{\wedge}$ & $428.6 \pm 175.9$ \\
\hline & & $100 \pm 24$ & $60 \pm 15$ & $160 \pm 42$ \\
\hline
\end{tabular}

The number of CFU of fungi obtained in the samples from the cellars and outdoor environment differed. The highest CFU was obtained with the Air IDEAL sampler and the lowest with the SAS Super 100 sampler. The results for all devices were otherwise different. Details of those results appear in Table 2.

From the air samples collected from the inside and outside the cellar the following strains of Acremonium, Aspergillus, Candida, Cladosporium, Fusarium, Mucor, and Penicillium were isolated. More Cladosporium species were collected with the MAS-100 sampler, whereas more Fusarium and Aspergillus species were collected with the Air IDEAL sampler. 
Details about those results appear in Table 3.

Table 3. Number of fungi species in air samples collected inside and outside the cellar.

\begin{tabular}{|c|c|c|c|}
\hline \multirow{2}{*}{ Place of Collection } & \multicolumn{3}{|c|}{ Species } \\
\hline & MAS 100 & SAS Super 100 & Air IDEAL \\
\hline \multicolumn{4}{|c|}{ Cellar I } \\
\hline Acremonium species & $8.7 \%$ & $30.8 \%$ & $40.6 \%$ \\
\hline Aspergillus fumigatus & $5.4 \%$ & $13.1 \%$ & $20.4 \%$ \\
\hline Aspergillus glaucus & $3.3 \%$ & $1.5 \%$ & \\
\hline Aspergillus nidulans & & $7.5 \%$ & $10.2 \%$ \\
\hline Aspergillus niger & $2.9 \%$ & $16.1 \%$ & $5.6 \%$ \\
\hline Aspergillus ochraceus & $2.1 \%$ & $1.7 \%$ & $5.4 \%$ \\
\hline Candida albicans & $1.7 \%$ & $4.2 \%$ & $1.2 \%$ \\
\hline Candida tropicalis & & $1.6 \%$ & $0.2 \%$ \\
\hline Candida crusei & & $0.3 \%$ & $0.5 \%$ \\
\hline Cladosporium species & $72.1 \%$ & & \\
\hline Fusarium species & & & $8.8 \%$ \\
\hline Mucor species & $1.2 \%$ & $2.4 \%$ & \\
\hline Penicillium species & $2.6 \%$ & $20.8 \%$ & $7.1 \%$ \\
\hline Number of species & 9 & 11 & 10 \\
\hline \multicolumn{4}{|c|}{ Cellar II } \\
\hline Acremonium species & $63.20 \%$ & & \\
\hline Aspergillus fumigatus & $21.00 \%$ & $75.6 \%$ & \\
\hline Aspergillus nidulans & $13.00 \%$ & & \\
\hline Aspergillus ochraceus & & & $42.3 \%$ \\
\hline Aspergillus versicolor & & & $20.7 \%$ \\
\hline Candida albicans & $1.50 \%$ & $13.2 \%$ & $3.2 \%$ \\
\hline Candida crusei & & & $1.2 \%$ \\
\hline Candida tropicalis & & & \\
\hline Mucor species & $1.30 \%$ & $11.2 \%$ & \\
\hline Fusarium species & & & $32.6 \%$ \\
\hline Number of species & 7 & 3 & 5 \\
\hline \multicolumn{4}{|c|}{ Cellar III } \\
\hline Acremonium species & $2.7 \%$ & & \\
\hline Alternaria alternata & $0.8 \%$ & $37.2 \%$ & $41.4 \%$ \\
\hline Aspergillus fumigatus & $1.1 \%$ & $10.5 \%$ & $10.1 \%$ \\
\hline Aspergillus nidulans & $1.2 \%$ & & $10.6 \%$ \\
\hline Aspergillus niger & $1.1 \%$ & $9.8 \%$ & $6.8 \%$ \\
\hline Aspergillus ochraceus & & $1.8 \%$ & $1.5 \%$ \\
\hline Candida albicans & $0.9 \%$ & $5.4 \%$ & $3.8 \%$ \\
\hline Candida crusei & $0.9 \%$ & $0.3 \%$ & $1.2 \%$ \\
\hline Candida tropicalis & $0.8 \%$ & $0.3 \%$ & $0.8 \%$ \\
\hline Cladosporium species & $10.0 \%$ & & \\
\hline Mucor species & $1.1 \%$ & & \\
\hline Penicillium species & $79.4 \%$ & $34.7 \%$ & $23.8 \%$ \\
\hline Number of species & 11 & 8 & 9 \\
\hline \multicolumn{4}{|c|}{ Outside the church } \\
\hline Acremonium species & & & $62.7 \%$ \\
\hline Aspergillus fumigatus & $68.8 \%$ & $37.9 \%$ & $34.9 \%$ \\
\hline Candida albicans & $16.7 \%$ & $2.2 \%$ & $1.6 \%$ \\
\hline Candida crusei & & $0.3 \%$ & \\
\hline Candida tropicalis & $14.5 \%$ & $0.7 \%$ & $0.8 \%$ \\
\hline Cladosporium species & & $58.9 \%$ & \\
\hline Number of species & 3 & 5 & 4 \\
\hline
\end{tabular}




\section{Discussion}

To monitor fungi in air pollution, three samplers were used in this study: the SAS Super-100 sampler [10,11], MAS-100 sampler [12], and Air IDEAL sampler [13]. Although our data reveal several differences in the number of fungi collected, isolates belonged mostly to Cladosporium, Aspergillus, Penicillium, and Candida. There are many factors that affect the collection efficiencies of portable microbial samplers.

To minimize the differences in the results among the tested air samplers, we used the same duration of air aspiration (1 min) to draw 100/L of air, the same height of the sampler placement (1.5 $\mathrm{m}$ above the floor), the same location for collecting air, and the same culture medium in all devices. However, we do not investigate any potential influence based on the samplers' construction. There are different cut-off sizes of the samplers. The SAS Super-100 has a cut-off size of $1.30 \mu \mathrm{m}$; the MAS-100 has $1.47 \mu \mathrm{m}$; and the Air IDEAL has a cut-off size of $3 \mu \mathrm{m}$. The numbers of impactor nozzles were the same. Different of cut-off sizes allow these samplers to collect most of the fungal spores [9].

Yao and Mainelis [9] compared cut-off sizes and collection efficiencies of seven portable microbial samplers (SMA MicroPortable, Bio-Culture, MicroFlow, MAS-100, Millipore Air Tester, SAS Super-180, and RCS High Flow Touch) for collecting polystyrene latex particles ranging from 0.5 to $9.8 \mu \mathrm{m}$ in aerodynamic size. For most samplers, they observed differences in collection efficiency using the traditional measurement method and the effective collection efficiency. All samplers collected $10 \%$ or less of $0.5 \mu \mathrm{m}$ particles on the agar medium. However, they concluded that most of the samplers investigated would be more efficient for collecting larger fungal spores.

In the collecting efficiency of air samplers, using the same culture medium is necessary because of the variations in cultivation efficiency with different culture media. Shintani et al. [16] found significant differences in cultivation efficiency using different media. In the present study, we used the same type of medium.

Gangneux et al. [17] compared the yields of four impactor air samplers (SAMPL'AIR MK2, Air IDEAL, MAS-100, and SAS Super-100) using two growth media (tryptic soy agar and malt extract agar) in the determination of fungal counts in hospital air. The authors did not find significant differences in fungal counts among the four devices. However, the use of malt extract agar in addition to tryptic soy agar significantly improved the fungal yield.

In the air samples collected from cellars in the present study, the number of fungi species isolated depended on the sampler. More Cladosporium species were collected with the MAS-100 sampler, whereas more Fusarium and Aspergillus species were collected with the Air IDEAL sampler.

The results of the present study suggest the need for more extensive air-pollutant evaluation studies using various measurement instruments. It is important that authors using a particular device should compare their results with the results obtained by other authors who used the same instrument, thus eliminating erroneous conclusions.

\section{Conclusions}

Significant differences among CFU/L values in tested sites depended on the sampler used.

The mycological analysis of cultures obtained from air samples suggests divergent isolations of fungi among different apparatuses. Further studies on air fungal contamination detected with the samplers are needed.

Author Contributions: Cecylia Łukaszuk and Elżbieta Krajewska-Kułak designed the experiments; Cecylia Łukaszuk, Elżbieta Krajewska-Kułak, Andrzej Guzowski, Wojciech Kułak, and Bogumiła Kraszyńska performed the experiments; Cecylia Łukaszuk, Elżbieta Krajewska-Kułak, and Wojciech Kułak analyzed the data; Elżbieta Krajewska-Kułak and Wojciech Kułak wrote the paper.

Conflicts of Interest: The authors declare no conflict of interest. 


\section{References}

1. Park, J.H.; Cox-Ganser, J.M. Mold exposure and respiratory health in damp indoor environments. Front. Biosci. 2011, 3, 757-771. [CrossRef]

2. Nevalainen, A.; Täubel, M.; Hyvärinen, A. Indoor fungi: Companions and contaminants. Indoor Air 2015, 25, 125-156. [CrossRef] [PubMed]

3. Walinder, R.; Norback, D.; Wessen, B.; Venge, P. Nasal lavage biomarkers: Effects of water damage and microbial growth in an office building. Arch. Environ. Health 2001, 56, 30-36. [CrossRef] [PubMed]

4. Bholah, R.; Subratty, A.H. Indoor biological contaminants and symptoms of sick building syndrome in office buildings in Mauritius. Int. J. Environ. Health Res. 2002, 12, 93-98. [CrossRef] [PubMed]

5. Zhiping, W.; Malmberg, P.; Larsson, B.M.; Larsson, K.; Larsson, L.; Saraf, A. Exposure to bacteria in swine-house dust and acute inflammatory reactions in humans. Am. J. Respir. Crit. Care Med. 1996, 154, 1261-1266. [CrossRef] [PubMed]

6. Wouters, I.M.; Douwes, J.; Thorne, P.S.; Heederik, D.; Doekes, G. Inter- and intraindividual variation of endotoxin- and beta(1-3)-glucan-induced cytokine responses in a whole blood assay. Toxicol. Ind. Health 2002, 18, 15-27. [CrossRef] [PubMed]

7. Polizzi, V.; Adams, A.; De Saeger, S.; Van Peteghem, C.; Moretti, A.; De Kimpe, N. Influence of various growth parameters on fungal growth and volatile metabolite production by indoor molds. Sci. Total Environ. 2012, 414, 277-286. [CrossRef] [PubMed]

8. Page, E.H.; Trout, D.B. The role of Stachybotrys mycotoxins in building-related illness. AIHAJ 2001, 62, 644-648. [CrossRef]

9. Yao, M.; Mainelis, G. Investigation of Cut-off Sizes and Collection Efficiencies of Portable Microbial Samplers. Aerosol Sci. Technol. 2006, 40, 595-606. [CrossRef]

10. Mehta, S.K.; Mishra, S.K.; Pierson, D.L. Evaluation of three portable samplers for monitoring airborne fungi. Appl. Environ. Microbiol. 1996, 62, 1835-1838. [PubMed]

11. Mehta, S.K.; Bell-Robinson, D.M.; Groves, T.O.; Stetzenbach, L.D.; Pierson, D.L. Evaluation of portable air samplers for monitoring airborne culturable bacteria. AIHAJ 2000, 61, 850-854. [CrossRef]

12. Krajewska-Kułak, E.; Gniadek, A.; Łukaszuk, C.R.; Macura, A.B.; Kułak, W. Wstępne porównanie wyników badań zanieczyszczenia powietrza grzybami z wykorzystaniem aparatu SAS SUPER 100 i MAS 1. Doniesienie wstępne. Mikol Lek 2009, 16, 34-39. (In Polish)

13. Yao, M.; Mailenis, G. Analysis of portable impactor performance for enumeration of viable bioaerosols. Occup. Environ. Hyg. 2007, 4, 514-524. [CrossRef] [PubMed]

14. Łukaszuk, C.; Krajewska-Kułak, E.; Guzowski, A.; Kraszyńska, B.; Grassmann, M.; Dobrowolski, R. Analysis of the incidence fungi in a crypt cemetery. J. Air Waste Manag. Assoc. 2015, 65, 1141-1147. [CrossRef] [PubMed]

15. Pastuszka, J.S.; Iwasiewicz, P.; Bragoszewska, E. Preliminary testing of a new bioaerosol sampler developed for the measurements of low and medium concentration levels of airborne bacteria and fungi. Environ. Protect. Eng. 2013, 39, 129-138.

16. Shintani, H.; Taniai, E.; Miki, A.; Kurosu, S.; Hayashi, F. Comparison of the collecting efficiency of microbiological air samplers. J. Hosp. Infect. 2004, 56, 42-48. [CrossRef] [PubMed]

17. Gangneux, J.P.; Robert-Gangneux, F.; Gicquel, G.; Tanquerel, J.J.; Chevrier, S.; Poisson, M.; Aupée, M.; Guiguen, C. Bacterial and fungal counts in hospital air: Comparative yields for 4 sieve impactor air samplers with 2 culture media. Infect. Control Hosp. Epidemiol. 2006, 27, 1405-1408. [CrossRef] [PubMed]

(C) 2017 by the authors. Licensee MDPI, Basel, Switzerland. This article is an open access article distributed under the terms and conditions of the Creative Commons Attribution (CC BY) license (http:/ / creativecommons.org/licenses/by/4.0/). 